\title{
A thematic analysis of compassion-focused imagery for people with personality disorder: inhibitors, facilitators and clinical recommendations.
}

Iona Naismith ${ }^{1}$, Shelley Kerr², Amanda Mwale ${ }^{3}$, \& Janet Feigenbaum²,3

${ }^{1}$ Universidad de los Andes, Bogota, Colombia

${ }^{2}$ North East London NHS Foundation Trust

${ }^{3}$ Research Department of Clinical, Educational and Health Psychology, University College London

*Requests for reprints should be addressed to: Iona Naismith, Universidad de los Andes, Carrera 1 No 18 -12 , Bogota, Colombia. Email: ij.naismith@uniandes.edu.co

Acknowledgements: The authors wish to thank Professor Paul Gilbert for his comments on the study design. 


\section{A thematic analysis of compassion-focused imagery for people with personality disorder: inhibitors, facilitators and clinical recommendations.}

Objectives. Compassion-focused therapy (CFT) is increasingly being offered for a range of conditions including personality disorders (PDs). A key process in CFT is to identify inhibitors to developing compassion and helping clients to overcome these. This study explores inhibitors and facilitators for clients with PD trialing compassion-focused imagery (CFI) over one week.

Methods. Fifty-three participants with a diagnosis of at least one PD engaged in CFI for the first time, before and after a negative mood-manipulation. Semi-structured group interviews and written openresponse questions were used to collect data on experiences of CFI, immediately following CFI and after one week of daily practice. Participants were invited to practice CFI daily for one week then complete further open-response questions online. Data were analyzed using thematic analysis.

Results. CFI generated both positive and negative experiences for clients. Six superordinate themes were identified regarding inhibitors of CFI: weak imagery ability, fear of compassion (with multiple subthemes), lack of compassionate experiences, and psychological symptoms. Most inhibitors remained following one-week of practice. Several facilitators of CFI were identified.

Conclusions. Clients with PD diagnoses face numerous inhibitors to CFI that occur transdiagnostically. Others may be more specific to this population, like fear of compassion focused on a dangerous "other". Some inhibitors are not overcome with practice alone, including weak imagery. Failure to assess for and address inhibitors prior to introducing CFI in this population risks causing harm to clients. 


\section{Key words: borderline personality disorder, compassion, compassion-focused therapy, mental imagery, personality disorders}

\section{Key Points:}

- Clients with PD diagnoses may face numerous inhibitors to CFI, including multiple fears of compassion, lack of compassionate experiences, weak mental imagery, and distress, which should be assessed and (if possible) addressed prior to introducing CFI.

- Several measures can significantly predict client response to CFI.

- Addressing compassion inhibitors may include: modelling compassion in the therapeutic relationship, guided discovery around inhibitors, normalizing difficulties, practicing compassion for others or selfcompassion before receiving compassion, personalizing techniques, directing clients with weak imagery abilities to other techniques, and using emotional-regulation prior to CFI. 
Personality disorders (PDs) are rooted in aversive early life experiences and characterized by long-term maladaptive patterns of behavior, cognition, affect, and/or interpersonal functioning (American Psychiatric Association, 2013). Shame and self-criticism are elevated or even characteristic of PDs including borderline, avoidant, narcissistic and dependent (Arntz, Weertman, \& Salet, 2011; Costa, Marôco, Pinto-Gouveia, Ferreira, \& Castilho, 2016; Ritter et al., 2014).

Dialectical behavioural therapy (DBT) treats shame and self-invalidation in borderline PD with validation and emotion-regulation training (Linehan, 2014). However, clinicians are increasingly incorporating compassion techniques into DBT and other PD treatments, from loving-kindness meditation (Hoffmann, Grossman \& Hinton, 2011) to group compassion-focused therapy (CFT; Gilbert, 2010a). Compassion can be experienced in three orientations: feeling compassion for others, receiving it from others, and self-compassion. It involves being sensitive to the suffering of oneself or others and committed to alleviate and prevent it (Gilbert, 2014, p19).

CFT recognizes that mammals have an emotion-regulation system involving the myelinated vagal nerve and hypothalamus, which responds to signals of safeness and care from others by downregulating the 'threat system' (sympathetic nervous system) so that we can approach and cooperate with others rather than seeing them as threats (Porges, 2007). CFT aims to activate this 'soothing system' to regulate shame, self-criticism and other threat-focused processes (Gilbert, 2010a).

Key components of CFT include: psychoeducation about human evolution and neurophysiology to reduce shame regarding one's emotional responses; exploring fears/resistances towards compassion; techniques to activate the parasympathetic nervous system; and practicing compassion in various ways (e.g. letter-writing, self-talk). CFT techniques lead to significant reductions in self-reported shame, selfcriticism and stress (Kirby, 2016), and can produce significant symptom reduction in PD populations 
(Feliu-Soler et al., 2017; Lucre \& Corten, 2013). Compassion-focused imagery (CFI), the focus of this paper, involves imagining or remembering people, places or objects directing compassion towards oneself. Practicing CFI for two weeks improves self-compassion more than simply practicing relaxation imagery, suggesting a specific effect (McEwan, Elander and Gilbert, 2018).

\section{Facilitators and inhibitors of compassion}

Despite promising findings, many clients report finding compassion challenging. Consequently, research has focused on compassion 'facilitators and inhibitors': factors that influence ease of generating compassion (Gilbert, 2017). This will enable identification of individuals/groups that need groundwork prior to compassion.

Self-criticism is associated with poor responses to compassion-focused imagery (CFI) in some studies (Gilbert, Baldwin, Irons, Baccus, and Palmer, 2006) although not in others (Naismith, Mwale, and Feigenbaum, 2018; Rockliff et al., 2008), which may reflect beliefs that self-compassion will cause one's standards to drop. Whilst conducting the present study, Duarte et al. (2015) published evidence that attachment insecurity predicts poorer responses to CFI. These individuals may have learned associations between compassion and threat, or experience yearning for compassion never given (Gilbert, 2010b).

Qualitative research with patients reporting trauma histories or diagnosed with anxiety, depression or PD have identified other compassion inhibitors. Most appear transdiagnostically, including negative self-perceptions, lack of relational-templates for compassion, or worrying about self-compassion leading to self-indulgent behavior (Lawrence \& Lee, 2014; Lucre \& Corten, 2013; McLean, Bambling \& Steindl, 2018; Pauley \& McPherson, 2010).

To date, no study has explored compassion inhibitors in PD. Some competencies that are necessary for compassion (Gilbert, 2014) may be particularly hard for this group, including distress 
sensitivity (ability to notice distress and distinguish emotions), distress tolerance, empathy, and skills to alleviate suffering in oneself or others. Individuals with BPD have difficulties with labelling and distinguishing emotions, perspective-taking, and emotion-regulation (Linehan, 2014). Various PDs including obsessive-compulsive, borderline and avoidant demonstrate low distress tolerance (Gratz, Tull, Matusiewicz, Breetz, \& Lejuez, 2013; Wheaton \& Pinto, 2017).

Given these findings, it is important to clarify how individuals with PD experience techniques to cultivate compassion. Although CFI is not offered as a standalone technique in clinical settings, studying it in isolation enables us to identify whether it alone produces positive experiences or requires groundwork (and if so, what inhibitors the groundwork should target).

One-session CFI significantly improved negative affect, self-esteem and self-reassurance in participants with clinical and subclinical psychosis (Ascone, Sundag, Schlier, \& Lincoln, 2017; Lincoln, Hohenhaus, \& Hartmann, 2013), suggesting potential promise in clinical populations. However, quantitative group analyses can mask individual variance in treatment response. Caution has been recommended when offering standalone CFI since in a non-clinical population, Rockliff, Gilbert, McEwan, Lightman and Glover (2008) found that half of participants showed physiological indicators of safeness during a single CFI trial, whilst the other half showed non-significant improvements (according to cortisol data) or even indicators of increased threat (according to heart-rate variability). However, the latter finding may not reflect a threat-response to compassion but rather general task-expectations concerns or conditioned fear of relaxation, since a subsequent study found that this effect also arises with relaxation imagery (Duarte, McEwan, Barnes, Gilbert, \& Maratos, 2015). If so, exposure to the task in a safe space may be sufficient to overcome these concerns.

\section{Present study}


This study explores experiences of 53 clients with PD diagnoses trialing CFI for the first time.

CFI was chosen for this study because imagery activates emotions more readily than verbal information (Holmes \& Mathews, 2010). To compare effects of different exercises and affective-states, we compared experiences during CFI 'from memory' versus 'from imagination' (Gilbert, 2010b), before and after a mood-manipulation. Data were collected during an initial trial and following one week of daily practice. Quantitative data were collected simultaneously and are published elsewhere (Naismith et al., 2018).

\section{Method}

\section{$\underline{\text { Participants }}$}

Fifty-three adults attending an outpatient PD service $(94.3 \%)$ or awaiting treatment $(5.7 \%)$ in greater London were recruited. Table 1 provides demographic and diagnostic details of the full sample, and the $17(32.1 \%)$ who remained in follow-up. As reported elsewhere (Naismith et al., 2018), attrition at followup was high but was not predicted by any factor measured. including self-compassion, fear of selfcompassion, self-criticism, or treatment duration.

All participants met DSM-V criteria for a diagnosis of a PD (American Psychiatric Association, 2013), which was a requirement for joining the waitlist or service. The majority $(n=46)$ had a primary diagnosis of BPD; 16 had multiple PDs. Clients with florid psychosis, learning disability or personality change due to head injury were excluded.

Clients in treatment were receiving standard DBT, including individual therapy and skills groups. None had previously tried CFT.

\section{Procedure}


Therapists informed clients attending the service of the study and explained that they would learn a new emotion-regulation technique. Clients on the waitlist were invited to participate via email. Seventeen testing sessions were run, ranging from 1 to 12 participants $(M=3.11, S D=2.67)$. Sessions were run by final-year trainee clinical psychologists external to the service (authors IN and AM), with previous experience delivering CFT groups. This approach was chosen since participants might have felt pressurized to participate in the study or underreport any negative experiences if it was being facilitated by participants' usual therapists. Supervision was offered by therapists experienced in DBT and CFT for PD (authors JF and SK).

Participants completed a demographics questionnaire, then brief guided relaxation to decrease anxiety and emulate normal group procedures. A definition of compassion (from Gilbert, 2010b) and its potential benefits were read aloud and provided on a handout. Participants were introduced to CFI, and informed that it can involve any sensory modality, and that distracting thoughts and non-clear pictures are common obstacles which can be reduced by gently returning attention to the task and focusing on other senses or on feelings generated (Gilbert, 2010b, p42). Testing-groups were alternately assigned to one of two CFI exercises from Gilbert (2010b): recalling a memory of receiving compassion $(n=25)$ or creating a perfectly-compassionate figure from imagination $(n=28)$. Following clinical guidelines, brief relaxingbreathing preceded CFI (McEwan \& Gilbert, 2016).

Participants were introduced to mental imagery through a short imagery exercise (imagining walking along a beach) followed by a practice of CFI, and invited to ask questions. Two CFI experimental trials followed; the second preceded by a negative mood-manipulation. Participants were briefly asked to recall a moment in which they felt rejected or abandoned by a loved one, but to choose "a typical everyday experience, not something that causes too much distress", and were invited to stop at any 
time. To withhold experimental aims from participants, the mood-manipulation was framed as another imagery exercise. However, a debrief was given at the end of the focus group (see below) in which participants were informed that since CFI is designed to help manage negative affect, they had been asked to recall an everyday situation that may trigger some emotions in order to determine whether it was more effective (or more difficult) when they were managing an everyday level of negative affect. They were invited to give feedback on this specifically.

After both trials, participants were invited to write down thoughts/feelings experienced, barriers and facilitators. Subsequently, a focus group was conducted and audio-recorded. Facilitators used the following semi-structured interview: (1) How did you find the exercises? (2) On which occasion was the image easiest to produce? (3) What (if any) image did you produce? (4) Did any emotions/thoughts/memories get in the way? (5) What might have helped? (6) Would you prefer group or individual sessions? (7) What barriers might arise in daily practice? Interviewers encouraged all participants to respond by asking "Does anyone else have similar or different views?" and validated any difficult feelings that arose.

At the end of the session, facilitators offered brief guidance (based on CFT literature) for how to respond to inhibitors that emerged, such as reminding participants that any new skill is tricky at first and requires practice, encouraging participants to view compassion as a basic need like a vitamin not something that must be earned, and acknowledging that thinking about compassion can be especially hard when we lacked compassion in early life.

Participants were invited to practice CFI daily for seven days using scripts of the exercises. Reminders were texted twice-daily. Afterwards, participants were emailed the following questions: 
(1) Did any thoughts/feelings/memories get in the way when practicing? (2) Did anything get in the way of you practicing? (3) What would have encouraged you to practice more? Participants who did not respond received daily email prompts for one week.

Data Analysis

The analysis focused on identifying participants' overall experiences, and CFI inhibitors/facilitators. Each group interview was transcribed verbatim. Transcripts and individuals' written responses were analyzed in NVivo using thematic analysis (Braun \& Clarke, 2006), selected as it aims to identify and describe patterns (themes) within the data. It entails familiarisation with the data; coding to identify important features; searching for broader 'themes'; refining them to ensure that they are representative and answered the research questions; assigning meaningful names to themes; and preparing a narrative of the findings grounded in examples. Trustworthiness of results is enhanced by comprehensive specification of methods, situating the sample, owning one's perspective as a researcher, grounding themes in examples, and conducting credibility checks (Elliot, Fischer \& Rennie, 1999).

Twelve of the 17 testing sessions were analysed by a single researcher (IN or AM). The others (selected randomly) were analysed by both researchers, permitting a credibility check during theme refinement by reading through one another's themes and comparing them to the data. Discrepancies were resolved through discussion and triangulation with previous literature. A third researcher (JF) reviewed the themes and compared them to compassion literature to enhance coherence and credibility.

Researchers play an active role in thematic analysis, therefore their perspectives shape themeidentification (Braun \& Clarke, 2006). All researchers were familiar with literature on inhibitors to compassionate imagery observed in other clinical populations (Gilbert, 2010b; Lucre \& Corten, 2013) and 
believed CFI could be helpful yet challenging for clients with PD. Researchers bracketed their assumptions and sought out similarities and differences across accounts.

\section{$\underline{\text { Results }}$}

Frequency of themes was similar across conditions, but we have noted how many participants in each condition mentioned a theme using (M) for 'compassion from memory' and (I) for imagination. Quotes are labelled with $(\mathrm{M})$ or $(\mathrm{I})$.

\section{Q1. What were participants' experiences of CFI?}

Recalled figures included a partner, a previous therapist, and pets in $(\mathrm{M})$, and inanimate objects (a beach, a ship), religious figures, fictional characters, or a future self in (I). Four themes emerged for this question: (1) Compassion, (2) Relaxation, (3) Difficult, (4) Negative emotions.

1) Compassion. Four participants described compassionate feelings including "warmth", "love", "safe", and "comfort":

'They showed deep reaching love towards me, a 'knowing' understanding of my true worth. They acknowledged suffering in me and I felt they too knew how it feels to suffer'.

'I felt an immense amount of love'.

2) Relaxation. Five described it as 'relaxing', elaborating: 'it's kind of refreshing and calm' or 'My stomach eased out of knots. My forehead soothed'.

3) Difficult. Ten described the task as 'difficult' or 'really tough' (six (I)). In contrast, four described it as 'easy' (two in each condition).

4) Negative emotions. Seven cited emotions such as 'rejection, loss, sadness' (five (M)). Five reported 'frustration' due to difficulties generating any imagery.

At follow-up, ten participants reported largely positive experiences with CFI: 
'In a stressful situation, I used the compassionate imagery visualisation spontaneously as a self-soothing exercise and found it effective' (M).

'Compassion has proved to be what I am missing and I find that it's helping'(I).

'I will use this skill as a lifelong skill' (M).

'I felt like I was in a safe place away from the harm of the world' (I).

Three described mixed experiences, such as finding it 'soothing' but also 'difficult'.

Four described mostly negative experiences:

'It negatively affected my moods for several hours to even the whole day' (M).

'Feel inadequate...can’t imagine anything' (I).

\section{Q2. What inhibitors to CFI could participants identify?}

Super- and sub-ordinate themes are described below. Table 2 presents themes and indicative quotations.

Inhibitor 1: Weak imagery ability. Six participants (four (I)), identified difficulties maintaining or creating an image. Several described this leading to frustration which became a further barrier:

'I struggle to imagine and that really does frustrate me, and then my mind just wanders off (I).

Nine reported during the initial session that CFI 'gets easier with time'. However, two reported an absence of imagery after one week of practice: 'no memories, just blankness'. One participant suggested prompting other senses besides visual and auditory: 'We have more than one sense, and you are only asking us to use two'. Others suggested providing sensory cues: 'a smell we could all relate to' like 'suncream', or 'a picture of a baby... or a dog', to enable them to 'compassionately relate to that specific thing'. 
Inhibitor 2: Fear of compassion. This was the most commonly described obstacle, with several subordinate themes identified. Nine expressed that Compassionate figures are unreliable (2a). Several linked this to past negative experiences:

'What got in the way was that at times people left me and that compassion doesn't last forever' (I).

Six believed that Compassionate figures are "manipulative" (2b). One identified confirmation bias, finding themselves 'looking for that evidence....to clarify what you believe' (M). Another mentioned difficulties mentalizing the figure's actions:

'I don't know what the person behind the eyes is thinking. Are they doing it because they want to shut me up? Or...because they genuinely love me? (M).

Occasionally, the three attempts in the initial session were enough to overcome the mistrust:

'To create someone who you're gonna trust....That's almost asking you to trust someone you don't know.

But the third time I went back to them, it did...feel a bit safer' (I).

Four overcome mistrust by removing specific triggers from their image: one imagined a conversation via telephone, while another stated:

'I wanted to hit the face and push it away from me....Instead, I imagined being held and the person's voice in French' (I).

At follow-up, this participant 'recorded the visualisation and altered the words of the text slightly to enable me to practise' (I). In contrast, another participant reported their figure was 'still manipulative and evil' (I) a week later.

Six described Feeling a burden or undeserving (2c), feeling they were 'dragging everybody down' with their distress (I) which triggered "shame". Another stated: 
'If I think of my mum being compassionate [towards me], the first thing I think of is all the things I've done wrong. So... why do I deserve someone to be compassionate and loving towards me? Cause I've made my mistakes...it's not really real, so you reject it. And I tried everyone' (M).

One participant overcame this by helping the compassionate figure in return:

'In my imagination, she also had her own problem and I was able to give compassion back, because for me it is very important that relationships are not one-sided' (I).

One continued to report 'feelings that I was not worth the compassion' (M) at follow-up.

Two participants described Fear of setting high standards $(2 d)$ which 'would be difficult for anyone to match', reflecting it would be important to remember that there is 'a completely different skill set you have to use when you are dealing with actual people' (I).

\section{Inhibitor 3: Lack of compassionate experiences.}

Five participants related their struggles to Lack of relational templates (3a), which inhibited CFI in both conditions:

'Trying to find something that is nice, warm, friendly, a bosom....it's an unreal thing for us' (M).

'Unless you have experienced it you can’t really imagine it...you are drawing from memories somewhere' (I).

One described generating an image, but no accompanying affect: 'I wasn't able to relate to the person as I haven't received a lot of compassion in the past' (I).

One suggested that practicing compassion for others might facilitate accepting compassion from others:

'Perhaps a preparatory exercise could involve remembering a time when you were kind or loving to someone or something else, and how you felt' (M).

More strongly, seven participants (five (I)), expressed Doubt that compassion exists (3b): 
'Even when they do sit down and listen, it feels like they accidentally got themselves into something they didn't want to...they feel obliged to continue...people don't really care, people are horrible nasty people (I).

Four attributed these beliefs to past experiences:

'This is when the negativity comes in, that you have had in your life, and you think, is there really anyone out there that is like that' (I).

One suggested that the perfection of the 'ideal other' increased difficulty:

'I felt as though I had to find this great thing. It was like, too far away. Too alien' (I).

Five described Sadness/resentment from lack of compassion (3c). This included 'rejection, loss, sadness' or 'grief', 'especially when you're using all those positive words like dependability, kindness, things that we never had'. One described self-doubt resulting from this:

'Is there something even worse wrong with me? Because I was supposed to have some sort of compassion somewhere along the line (M).

'Anger' and 'resentment' towards those who had not been compassionate were also mentioned:

'I'm thinking about my dad and other people in my life that aren't like that... I'm starting to feel a little bit of resentment towards them and I feel guilty for thinking that' (I).

Theme (3b) was the most common barrier reported at follow up. Five participants described intrusive memories from childhood and adulthood, including 'emotional abuse' (I), a 'lack of compassion' from parents (M), or 'relationships that have broken down' (M), making participants feel 'angry and then very sad'.

Inhibitor 4: Distressing affect/cognitions. Twelve participants (seven (M)), found CFI harder after the mood manipulation because of intrusive images of the recalled event: 'the critical image in between, I kept going back to it', or because distress triggered a desire for isolation: 
'I trusted [the figure], but when I'm down I can't stand people around me trying to comfort me or touch me' (I).

When queried, most participants stated that this experience reflected their typical negative affect, yet one stated that the mood-manipulation created falsely vivid images: 'It is a different drift. Maybe because I pictured it so clearly'.

Some recommended that CFI be preceded by other emotion-regulation strategies such as grounding or funny images. Two in (I) suggested also using CFI when not distressed, to avoid 'associating [the figure] with feeling down'.

Inhibitor 5: Lack of distress. Conversely, four participants (three (I)) found that CFI was easier following the mood-manipulation because the compassionate figure 'had something to soothe me about', whilst premanipulation they were thinking 'What do I want them for?'.

Inhibitor 6: Psychological symptoms. Some obstacles arose in relation to the broader context of groupwork, new tasks, or relaxation. These reflected cognitions and emotions that characterize many psychological disorders, such as self-criticism and perfectionism (6a):

'What kind of a useless person am I that I can't even imagine someone being kind to me?' (I).

'I want to do it perfectly, so it frustrates me that I can't' (I).

Five participants found that the group format reduced self-judgement through normalizing difficulties:

'Hearing you say 'I struggled as well' was reassuring' (I).

In contrast, two stated a preference for 1:1 modality because 'I don't like being upset in front of other people' (I).

One participant described discomfort with relaxation $(6 b)$ :

'When I try to relax, panic sets in... I'm used to feeling intense, and if I go into relaxation mode...it's an out of control feeling. There's always consequences: one good day and you'll pay the price' (I). 


\section{$\underline{\text { Discussion }}$}

CFT is increasingly being integrated into PD treatment, but little evidence exists on how this population experience compassion-based therapies. This study identified a range of inhibitors that may be particularly characteristic of PD (e.g. fear of manipulation), some transdiagnostic inhibitors (e.g. weak imagery abilities), and several facilitators.

\section{$\underline{\text { CFI outcomes and acceptability in PD }}$}

A minority of participants described CFI positively at the initial session. Ten participants (59\%) at follow-up reported largely positive experiences. This suggests that without prior groundwork, CFI will only be effective for a small proportion of individuals with PD. Seven participants at follow-up (41\%) and many at the initial session reported mixed or mostly negative reactions, including 'frustration' due to struggling with CFI or 'sadness' about compassion they lacked in childhood, resembling the mixed responses reported elsewhere (Duarte et al., 2015; Rockliff et al., 2008).

$\underline{\text { Inhibitors and facilitators of CFI }}$

Gilbert (2014) theorized that compassion involves two components (motivation to identify and engage with distress, and skills in distress alleviation). Each requires numerous competencies which, when absent, inhibit compassion. Six overarching inhibitors of CFI were identified in this study: Weak imagery ability, Fear of compassion, Lack of compassionate experiences, Distressing affect/cognitions, Lack of distress, and Psychological symptoms.

Fear of compassion (2) was the most commonly-identified barrier to CFI. In other client populations, fear of self-compassion typically centres around fear of losing self-criticism and associated self-identity, or feeling undeserving (Lawrence \& Lee, 2014). This study identified several distinct fears centred around the compassionate "other": perceiving others as unreliable (2a), manipulative (2b), or 
insufficient compared to the ideal compassionate other (2d), along with feeling undeserving (2c) as identified previously. These closely resemble early maladaptive schemas of abandonment; mistrust/abuse; emotional deprivation, and defectiveness/shame, respectively (Young, 2003), and is compatible with evidence linking BPD and Avoidant PD (the most common primary and secondary PDs in this sample) specifically to mistrust/abuse, defectiveness/shame and abandonment schemas (Jovev \& Jackson, 2004; Lawrence, Sabura-Allen, and Chanen, 2010).

Some participants overcame fears of compassion through CFI practice, but others continued to report these at follow-up. These fears should thus be addressed beforehand. Therapy should target specific fears of compassion, since despite participants having completed on average 6.5 months of DBT, treatment length was not associated with better quantitative outcomes (Naismith et al., 2018). Negative working models of others can be challenged using the therapeutic relationship as an example (Berry \& Danquah, 2016). Recalling small moments of compassion in daily life might be easier than recalling past compassion or imagining a perfect compassionate figure. Indeed, DBT recommends building trust for others by perceiving trustworthiness dialectically, not in extremes (Linehan, 2014).

Results might have differed had tasks involved self-compassion rather than compassion from others, especially for individuals with mistrust/abandonment fears. However, this might still be challenging since shame and self-criticism are elevated in various PDs (Arntz, Weertman, \& Salet, 2011; Jovev \& Jackson, 2004). BPD clients often reject cognitive restructuring intended to identify their lovable characteristics, so therapists should instead build the belief that all humans are lovable (Linehan, 2014). Some clients report psychoeducation about "common humanity" (the idea that mistakes and imperfections are part of human nature) helpful in overcoming feelings of un-deservingness (Lawrence \& Lee, 2014). 
Participants reporting a Lack of relational templates (3a) were uncertain "what compassion looks like". This reflects findings that low self-compassion and self-reassurance are uniquely predicted by lack of warmth in childhood rather than maltreatment or invalidation (Irons et al. 2006; Kelly \& Dupasquier, 2016; Naismith, Zarate-Guerrero \& Feigenbaum, 2019; Richter et al., 2009). Other client groups report that the therapeutic relationship helps by modelling compassion (Lawrence \& Lee, 2014; McLean, Bambling \& Steindl, 2018). This may also help overcome Doubt that compassion exists (3b).

Sadness/resentment from lack of compassion (3c) was reported at initial trials and follow-up. Therapists should spend time validating these difficulties prior to CFI. Processing difficult memories, supported by mindful acceptance and compassion will likely help more than avoidance (Berking, Neacsiu, Comtois, \& Linehan, 2009), but should be done within an established therapeutic relationship (Berry \& Danquah, 2016).

Many participants reported inhibitory effects of Weak imagery ability (1). Accordingly, participants reporting non-vivid imagery across various tasks experience less positive affect following CFI (Naismith et al., 2018; Naismith, Duran-Ferro, Ingram \& Jimenez-Leal, 2019). Although the CFT training manual suggests that compassionate affect "will follow" with practice, even with low imagery vividness (Gilbert, 2010b), some participants nonetheless reported negative affect due to a lack of imagery even at follow-up. Individual differences in imagery abilities have been attributed to biological differences in the brain's sensory areas and voluntary control mechanisms that activate them (Andrade, May, Deeprose, Baugh \& Ganis, 2014). Some studies find that practice increases imagery vividness (Torkan et al., 2014) but others report no improvement (Rademaker \& Pearson, 2012). Clients experiencing difficulties may benefit more from non-imagery CFT techniques until this is researched further. 
Inhibitory effects of Distressing affect/cognitions (4) is corroborated by quantitative data collected in this sample (Naismith et al., 2018) and by other studies (Pauley and McPherson, 2010). Distresstolerance is essential to compassion, since avoiding distress or becoming overwhelmed prevents one from responding with empathy (Neff, 2003). One participant reported having to be alone when upset, which may reflect receiving invalidation when distressed. Such individuals should explore the idea that a perfect compassionate other can handle even their most overwhelming emotions.

One novel finding is that some clients perceive a Lack of Distress (5) to be a barrier. This highlights the importance of encouraging clients to view compassion not as a luxury but an essential resource like vitamins (Gilbert, 2010c).

$\underline{\text { Strengths and limitations }}$

A qualitative approach enabled in-depth exploration of ideas such as different fears of compassion, which will help inform formulation. Best-practice guidelines for qualitative research were followed to increase trustworthiness, although due to time limitations, a 'member check' was not conducted.

Use of group interviews (with a mean size of three participants) may have supported discussions through clients scaffolding and triggering one another's ideas. Individual written responses were also invited to avoid data loss due to social inhibition.

Since the sample predominantly had a primary diagnosis of BPD, generalizability to other PDs is limited. Using group interviews as the primary data-collection method prevented categorization of responses according to participant diagnosis.

Inclusion of a follow-up was a strength, but generalization of results is limited by high attrition. However, as noted previously, participants who completed follow-up did not significantly differ on key variables from those who dropped out. Dropout is high in PD samples (Crawford et al., 2009), and rates 
may have been higher in this study since the intervention was not administered in the context of a developed therapeutic relationship and a formulation that includes developing compassion. However, all participants recruited whilst in treatment (94.3\% of the sample) were informed about the study by their therapists and told that it may help. Another difference between the study and typical clinical practice is that follow-up data were requested via email rather than scheduled in-person sessions, so may be influenced by infrequent checking of emails or low motivation to respond by this modality.

\section{Clinical implications}

Some clients experienced frustration due to lack of images, which sometimes was not overcome through practice. Thus, non-imagery techniques may be more effective. Participants may benefit more from CFI following emotion-regulation techniques. Studies of BPD clients have found that overwhelming emotions are the main barrier to coping skills but can be overcome by personalising skills and integrating them into a repertoire (Barnicot, Couldrey, Sandhu, \& Priebe, 2015).

CFI practice alone mostly failed to overcome fear of compassion. Different techniques may be appropriate depending on the underlying inhibitory process. A positive therapeutic relationship may help by providing a relational template of compassion, challenging negative working models of others, and/or extinguishing conditioned fear towards compassion. Guided discovery and behavioural experiments may facilitate cognitive flexibility around mistrusting others or being undeserving. Motivational interviewing could resolve ambivalence about compassion (Steindl, Kirby \& Tellegen, 2018). Processing grief around lack of past compassion may also be important. Personalizing exercises to reduce triggers or avoiding using a "perfectly compassionate" figure at first may help.

To avoid negative reactions, therapists should assess for inhibitors of compassion and where possible, address them prior to introducing CFI. Validated measures of social safeness and self- 
reassurance may be useful since these have been significantly negatively associated with response to CFI (Naismith et al., 2019; Rockliff et al., 2008). High self-criticism is associated with response to CFI in some studies, but not after controlling for self-reassurance, so may be less important (Naismith et al., 2019). Fear of self-compassion did not predict CFI in a previous study of the present sample (Naismith et al., 2018), which may reflect that this scale measures many different processes, only some of which are relevant for this population (Asano et al., 2017). Additionally, evaluating clients' compassion competencies such as distress sensitivity, distress tolerance and empathy can enable clinicians to identify therapy targets prior introducing more challenging tasks like CFI (Gilbert, 2014).

Self-compassion, compassion for others, and compassion from others are distinct processes (Gilbert, 2017) and each may be experienced differently by clients. Compassion for others may be a helpful first step towards developing the other domains.

\section{$\underline{\text { Future research }}$}

Further studies are required to understand the mechanisms by which compassion inhibitors are overcome. Researchers might explore how clients with PD experience compassion for others and from self; and whether practice in one domain can impact the others. Future research could also establish whether practice enhances CFI vividness.

\section{Conclusions}

This study offers the first qualitative findings on client experiences of CFI specifically, and adds to a small evidence base regarding CFT techniques for PD. Some inhibitors found in this study have been little-explored (e.g. weak imagery abilities following practice) or not previously identified (e.g. fear of manipulation); the latter may be especially characteristic of PD. Regular CFI practice may offer an 
effective treatment adjunct for PD, but assessing and addressing inhibitors beforehand is essential to avoid adverse outcomes.

\section{Ethical statement}

All authors declare that they have no conflict of interest.

Informed consent was obtained from all participants.

Research Ethics Committee London provided ethical approval.

All procedures performed in this study were in accordance with the ethical standards of the national research committee and with the 1964 Helsinki declaration and its later amendments or comparable ethical standards. 


\section{$\underline{\text { References }}$}

American Psychiatric Association (2013). Diagnostic and statistical manual of mental disorders (5th ed.). Arlington, VA: American Psychiatric Publishing.

Andrade J., May, J., Deeprose, C., Baugh, S.J. \& Ganis, G. (2014). Assessing vividness of mental imagery: The Plymouth Sensory Imagery Questionnaire. British Journal of Psychology, 105(4): 547-63.

Arntz, A., Weertman, A., \& Salet, S. (2011). Interpretation bias in cluster-C and borderline personality disorders. Behaviour Research and Therapy, 49(8), 472-481. doi: 10.1016/j.brat.2011.05.002

Barnicot, K., Couldrey, L., Sandhu, S., \& Priebe, S. (2015). Overcoming barriers to skills training in borderline personality disorder: a qualitative interview study. PloS One, 10(10): e0140635. doi: 10.1371/journal.pone.0140635

Berking, M., Neacsiu, A., Comtois, K.A., \& Linehan, M. M. (2009). The impact of experiential avoidance on the reduction of depression in treatment for borderline personality disorder. Behaviour Research and Therapy, 47(8), 663-670. doi:10.1016/j.brat.2009.04.011

Berry, K. \& Danquah, A. (2016) Attachment-informed therapy for adults: Towards a unifying perspective on practice. Psychology and Psychotherapy: Theory, Research and Practice, 89, 15-32. doi:10.1111/papt.12063

Braun, V., \& Clarke, V. (2006). Using thematic analysis in psychology. Qualitative Research in Psychology, 3(2), 77-101. Doi: 10.1191/1478088706qp063oa

Crawford, M.J., Price, K., Gordon, F., Josson M, Taylor B, Bateman A... \& Moran P.(2009). Engagement and retention in specialist services for people with personality disorder. Acta Psychiatrica Scandinavica., 119: 304-311. doi: 10.1111/j.1600-0447.2008.01306. 
Duarte, J., McEwan, K., Barnes, C., Gilbert, P., \& Maratos, F.A. (2015). Do therapeutic imagery practices affect physiological and emotional indicators of threat in high self-critics? Psychology and Psychotherapy: Theory, Research and Practice, 88(3), 270-284. doi: 10.1111/papt.12043

Elliott, R., Fischer, C.T., Rennie, D.L. (1999). Evolving guidelines for publication of qualitative research studies in psychology and related fields. British Journal of Clinical Psychology, 38(3):215-29.

Gilbert, P. (2010a). Compassion Focused Therapy: The CBT Distinctive Features Series. London: Routledge.

Gilbert, P. (2010b). Training our minds in, with and for compassion. An introduction to concepts and compassion-focused exercises.

Gilbert, P. (2014). The origins and nature of compassion focused therapy. British Journal of Clinical Psychology, 53, 6-41. Doi:10.1111/bjc.12043.

Gilbert, P. (2017). Compassion: Concepts, Research and Applications. Routledge, London.

Gilbert, P., Baldwin, M. W., Irons, C., Baccus, J. R., \& Palmer, M. (2006). Self-criticism and selfwarmth: An imagery study exploring their relation to depression. Journal of Cognitive Psychotherapy, 20, 183-200. Doi: 10.1891/jcop.20.2.183

Hoffmann, S. G., Grossman, P., \& Hinton, D. E. (2011). Loving-kindness and compassion meditation: Potential for psychological intervention. Clinical Psychology Review, 13, 1126-1132. doi:10.1016/j.cpr.2011.07.003

Holmes, E.A., \& Mathews, A. (2010). Mental imagery in emotion and emotional disorders. Clinical Psychology Review, 30(3), 349-362. Doi: 10.1016/j.cpr.2010.01.001 
Irons, C., Gilbert, P., Baldwin, M.W., Baccus, J.R \& Palmer, M. (2006). Parental recall, attachment relating and self-attacking/self-reassurance: Their relationship with depression. British Journal of Clinical Psychology, 45 (Pt 3), 297-308. Doi: 10.1348/014466505X68230

Jovev, M., \& Jackson, H.J. (2004). Early maladaptive schemas in personality disordered individuals. Journal of Personality Disorders, 18(5), 467-478. Doi: 10.1521/pedi.18.5.467.51325

Kelly, A.C. \& Dupasquier, J. (2016). Social safeness mediates the relationship between recalled parental warmth and the capacity for self-compassion and receiving compassion. Personality and Individual Differences, 89, 157-161. Doi: 10.1016/j.paid.2015.10.017

Lawrence, V.A., \& Lee, D. (2014). An exploration of people's experiences of compassion-focused therapy for trauma, using Interpretative Phenomenological Analysis. Clinical Psychology \& Psychotherapy, 21(6), 495-507. doi: 10.1002/cpp.1854

Lawrence, K.A., Sabura Allen, J., \& Chanen, A.M. (2010). A study of maladaptive schemas and borderline personality disorder in young people. Cognitive Therapy and Research, 24(6), 758-799. Doi: 10.1521/pedi.2010.24.6.785.

Linehan, M.M. (2014) . DBT skills training manual (2nd ed.). New York, New York: Guilford Press. Longe, O., Maratos, F.A., Gilbert, P., Evans, G., Volker, F., Rockliffe, H \& Rippon, G.(2010). Having a word with yourself: Neural correlates of self-criticism and self-reassurance. NeuroImage ,49, 1849-1856. Lucre, K.M., \& Corten, N. (2013). An exploration of group compassion-focused therapy for personality disorder. Psychology and Psychotherapy - Theory Research and Practice, 86(4), 387-400. doi: $10.1111 / \mathrm{j} .2044-8341.2012 .02068$.

McEwan, K. \& Gilbert, P. (2016). A pilot feasibility study exploring the practising of compassionate 
imagery exercises in a nonclinical population. Psychology and Psychotherapy: theory, research and practice, 89, 239-243. doi: 10.1111/papt.12078.

McEwan, K., Elander, J. \& Gilbert, P. (2018). Evaluation of a web-based self-compassion intervention to reduce student assessment anxiety. Interdisciplinary Education and Psychology, 2(1):6. doi: 10.31532/InterdiscipEducPsychol.2.1.006

McLean, L., Bambling, M. \& Steindl, S. R. (2018). Perspectives on self-compassion from adult female survivors of sexual abuse and the counselors who work with them. Journal of Interpersonal Violence, 124. Doi: $10.1177 / 0886260518793975$

Naismith, I., Duran Ferro, C., Ingram, G., \& Jimenez Leal, W. (2019). Compassion-focused imagery reduces shame and is moderated by shame, self-reassurance and multisensory imagery vividness. Research in Psychotherapy: Psychopathology, Process and Outcome. Advanced online publication. Doi: 10.4081/ripppo.2019.329

Naismith, I., Mwale, A., Feigenbaum, J. (2018). Inhibitors and facilitators of compassion-focused imagery in personality disorder. Clinical Psychology \& Psychotherapy, 25(2): 283-291. doi: 10.1002/cpp.2161.

Naismith, I., Zarate-Guerrero, S. \& Feigenbaum, J. (2019). Abuse, invalidation and lack of early warmth show distinct relationships with self-criticism, self-compassion and fear of selfcompassion in personality disorder. Clinical Psychology \& Psychotherapy. Advanced online publication. Doi: 10.1002/cpp.2357

Neff, K.D.(2003). Development and validation of a scale to measure self-compassion. Self and Identity, 2, 223-250. 
Pauley, G., \& McPherson, S. (2010). The experience and meaning of compassion and self-compassion for individuals with depression or anxiety. Psychology and Psychotherapy-Theory Research and Practice, 83(2), 129-143. doi: 10.1348/147608309x471000.

Rademaker, R.L., \& Pearson, J. (2012). Training visual imagery: improvements of metacognition, but not imagery strength. Frontiers in Psychology, 3. doi: 10.3389/fpsyg.2012.00224

Richter, A., Gilbert, P. \& McEwan, K. (2009). Development of an early memories of warmth and safeness scale and its relationship to psychopathology. Psychology and Psychotherapy:

Theory, Research and Practice, 82, 171-184. doi: 10.1348/147608308X395213.

Ritter, K., Vater, A., Ruesch, N., Schroeder-Abe, M., Schuetz, A., Fydrich, T., . . Roepke, S. (2014).

Shame in patients with narcissistic personality disorder. Psychiatry Research, 215(2), 429-437. doi:

10.1016/j.psychres.2013.11.019

Steindl, S.R., Kirby, J. N. \& Tellegen, C. (2018). Motivational interviewing in compassion-based interventions: Theory and practical applications. Clinical Psychologist, 22(3), 265-279. doi:

$10.1111 /$ cp. 12146

Torkan, H., Blackwell, S. E., Holmes, E. A., Kalantari, M., Neshat-Doost, H. T., Maroufi, M., \& Talebi, H. (2014). Positive Imagery Cognitive Bias Modification in Treatment-Seeking Patients with Major Depression in Iran: A Pilot Study. Cognitive therapy and research, 38(2), 132-145. Doi: 10.1007/s10608014-9598-8.

Tracy, J.L., Robins, R.W. (2004). Putting the self into self-conscious emotions: a theoretical model. Psychology Inquiry, 15 (2), 103-125. Doi: 10.1207/s15327965pli1502_01 
Wheaton, M.G., \& Pinto, A. (2017). The role of experiential avoidance in obsessive-compulsive personality disorder traits. Personality Disorders: Theory, Research, and Treatment, 8(4), 383-388. Doi: 10.1037/per0000200

Young, J.E., Klosko, J., \& Weishaar, M.E. (2003). Schema therapy: A practitioner's guide. New York: Guilford. 
Table 1. Demographic and diagnostic information

\begin{tabular}{|c|c|c|}
\hline Variable & $\begin{array}{l}\text { Initial session } \\
(n=53)\end{array}$ & $\begin{array}{l}\text { Follow-up } \\
(n=17,32.1 \%)\end{array}$ \\
\hline \multicolumn{3}{|l|}{ Age (years) } \\
\hline Range & 18 to 57 & 19 to 57 \\
\hline$M(S D)$ & $32(11.1)$ & $34(10.6)$ \\
\hline \multicolumn{3}{|l|}{ Sex } \\
\hline Female & 44 & 15 \\
\hline Male & 9 & 2 \\
\hline \multicolumn{3}{|l|}{ Treatment status } \\
\hline Attending PD service & $50(94.3 \%)$ & $17(100 \%)$ \\
\hline Awaiting treatment & $3(5.7 \%)$ & 0 \\
\hline \multicolumn{3}{|c|}{$\begin{array}{l}\text { Length of current treatment } \\
\text { cycle (months) }\end{array}$} \\
\hline Range & 0 to 22 & 0 to 22 \\
\hline$M(S D)$ & $6.5(5.2)$ & $6.7(6.1)$ \\
\hline \multicolumn{3}{|l|}{ Ethnicity } \\
\hline White & $40(75.5 \%)$ & $14(82.4 \%)$ \\
\hline Asian or Asian British & $6(11.3 \%)$ & $1(5.9 \%)$ \\
\hline
\end{tabular}




\begin{tabular}{|c|c|c|}
\hline Black or black British & $3(5.6 \%)$ & 0 \\
\hline Mixed & $2(3.8 \%)$ & $1(5.9 \%)$ \\
\hline Other & $2(3.8 \%)$ & 0 \\
\hline \multicolumn{3}{|l|}{ Primary diagnosis } \\
\hline$B P D$ & 47 (88.7\%) & $16(94.1 \%)$ \\
\hline Narcissistic PD & $3(5.7 \%)$ & $1(5.8 \%)$ \\
\hline $\begin{array}{l}\text { Personality Disorder Not } \\
\text { Otherwise Specified }\end{array}$ & $1(1.9 \%)$ & 0 \\
\hline Data unavailable & $2(3.8 \%)$ & 0 \\
\hline \multicolumn{3}{|l|}{$\begin{array}{l}\text { Most common comorbid } \\
\text { diagnoses }\end{array}$} \\
\hline Generalised Anxiety Disorder & $12(22.6 \%)$ & $5(29.4 \%)$ \\
\hline Major Depressive Disorder & $9(17.0 \%)$ & $4(23.5 \%)$ \\
\hline Avoidant $P D$ & $9(17.0 \%)$ & $3(17.6 \%)$ \\
\hline$O C P D$ & $5(9.4 \%)$ & $2(11.8 \%)$ \\
\hline
\end{tabular}




\begin{tabular}{|l|l|l|}
\hline CFI exercise trialed & & \\
\hline Ideal compassionate other & $28(52.8 \%)$ & $8(47.1 \%)$ \\
\hline Compassion from memory & $25(47.1 \%)$ & $9(52.9 \%)$ \\
\hline
\end{tabular}


Table 2. Subordinate and superordinate themes from research question 2

\begin{tabular}{|c|c|c|}
\hline $\begin{array}{l}\text { Superordinate } \\
\text { themes }\end{array}$ & $\begin{array}{l}\text { Subordinate } \\
\text { themes }\end{array}$ & Indicative quotations \\
\hline \multicolumn{2}{|c|}{ 1) Weak imagery ability } & $\begin{array}{l}\text { "I know what was said, but I can't hear anything, or } \\
\text { reproduce things in any way". }\end{array}$ \\
\hline \multirow[t]{5}{*}{$\begin{array}{l}\text { 2) Fear of } \\
\text { compassion }\end{array}$} & $\begin{array}{l}\text { a) Compassionate figures } \\
\text { are "unreliable" }\end{array}$ & $\begin{array}{l}\text { "What got in the way was that at times people left me } \\
\text { and that compassion doesn't last forever". }\end{array}$ \\
\hline & $\begin{array}{l}\text { b) Compassionate figures } \\
\text { are "manipulative" }\end{array}$ & $\begin{array}{l}\text { "I don't know what the person behind the eyes is } \\
\text { thinking. Are they doing it because they want to shut } \\
\text { me up?" }\end{array}$ \\
\hline & $\begin{array}{l}\text { c) Feeling a burden or } \\
\text { undeserving. }\end{array}$ & $\begin{array}{l}\text { "Why do I deserve someone to be compassionate and } \\
\text { loving towards me? 'Cause I've made my mistakes." }\end{array}$ \\
\hline & & $\begin{array}{l}\text { "I can't take validation from anybody else...I feel } \\
\text { ashamed”. }\end{array}$ \\
\hline & $\begin{array}{l}\text { d) Fear of setting high } \\
\text { standards }\end{array}$ & $\begin{array}{l}\text { "Maybe there is a risk of taking it too far and relying } \\
\text { quite heavily on it. } \\
\text { 'Cos obviously the compassionate person or idea that } \\
\text { you imagine is almost impossible to match with } \\
\text { anybody" }\end{array}$ \\
\hline
\end{tabular}

3) Lack of

a) Lack of relational 'You only know from what you've been taught, you 
compassionate templates

experiences

\section{4) Distressing "When I'm down I can't \\ affect/cognitions stand people around me \\ trying to comfort me or \\ touch me".}

5) Lack of distress. "I found the last

visualisation a lot

easier...because they had

something to soothe me

about."

6) Psychological

a) Self-

symptoms can only have a memory, a realization of something that you have in the past."

"People don't really care, people are horrible nasty

people"

“It makes you look at what you haven't got, and then

you are thinking, is there something even worse wrong with me because I was supposed to have some sort of compassion somewhere along the line". 
intense, and if I go into relaxation mode...it's an out of control feeling - there's always consequences - one good day and you'll pay the price". 